(C) Dereito Vol.29, n02:9-27 (Xullo-Decembro, 2020) • ISSN 1132-9947

\title{
A RELEVÂNCIA DO PORTAL BASE, À LUZ DOS PRINCÍPIOS FUNDAMENTAIS DA CONTRATAÇÃO PÚBLICA E DO PROCEDIMENTO DE FORMAÇÃO DOS CONTRATOS PÚBLICOS EM PORTUGAL
}

The relevance of the base portal, in the light of the fundamental principles of public procurement and of the procedure for forming public contracts in Portugal

La relevancia del portal base, a la luz de los principios fundamentales de la contratación pública y del procedimiento de formación de contratos públicos en Portugal

DOI: http://dx.doi.org/10.15304/dereito.29.2.7144

\author{
PATRÍcia Anjos AZEVEdo \\ Professora Adjunta Convidada \\ Escola Superior de Tecnologia e Gestão do Politécnico do Porto \\ patricia anjos azevedo86@hotmail.com
}

DAVIDE RUA CARNEIRO

Professor Adjunto

Escola Superior de Tecnologia e Gestão do Politécnico do Porto dcarneiro@estg.ipp.pt

\section{Resumen}

En la formación y ejecución de los contratos públicos deben respetarse los principios de legalidad, la búsqueda del interés público, la imparcialidad, proporcionalidad, buena fe, protección de la confianza, sostenibilidad y responsabilidad, competencia, publicidad y transparencia, igualdad de trato y no discriminación. El procedimiento de formación del contrato constituye la sucesión ordenada de actos que contribuyen a la formación, celebración y producción de la plena eficacia jurídica de un contrato público. El legislador define los momentos que constituyen la tramitación del procedimiento, en una lógica de transparencia, garantizando la imparcialidad e igualdad de trato y el acceso al procedimiento y la adecuación procesal.

El objetivo del portal Base es difundir información sobre los contratos públicos celebrados en Portugal sujetos al régimen del Código de Contratos Públicos. Para cumplir con este objetivo, el portal es una herramienta tecnológica que centraliza, en un espacio virtual, información sobre la formación y ejecución de contratos públicos.

Palabras clave: Portal Base; Principios; la contratación pública; procedimiento; la contratación pública.

\section{Abstract}

The formation and execution of public contracts has to respect the principles of legality, the pursuit of the public interest, impartiality, 
proportionality, good faith, protection of trust, sustainability and responsibility, competition, advertising and transparency, equal treatment and non-discrimination. The contract formation procedure constitutes the orderly succession of acts that contribute to the formation, conclusion and production of full legal effectiveness of a public contract. The legislator defines the moments that constitute the course of the procedure, in a logic of transparency, guaranteeing impartiality and equal treatment and access to the procedure and the procedural adequacy.

The objective of the Base portal is to disseminate information on public contracts concluded in Portugal subject to the Public Contracts Code regime. To fulfill this objective, the portal is a technological tool that centralizes, in a virtual space, information regarding the formation and execution of public contracts.

Keywords: Base platform; principles; public procurement; procedure; public contracts.

\section{Resumo}

$\mathrm{Na}$ formação e execução dos contratos públicos devem ser respeitados os princípios da legalidade, prossecução do interesse público, imparcialidade, proporcionalidade, boa-fé, tutela da confiança, sustentabilidade e responsabilidade, concorrência, publicidade e transparência, igualdade de tratamento e não-discriminação. O procedimento de formação de contratos constitui a sucessão ordenada de atos que concorrem para a formação, a conclusão e a produção de uma plena eficácia jurídica de um contrato público. O legislador define os momentos que constituem a tramitação do procedimento, numa lógica de transparência, garantindo a imparcialidade e a igualdade de tratamento e de acesso ao procedimento e a adequação procedimental.

O objetivo principal do portal Base é divulgar informação sobre os contratos públicos celebrados em Portugal sujeitos ao regime do Código dos Contratos Públicos. Para dar cumprimento a este objetivo, o portal constitui-se como uma ferramenta tecnológica que centraliza, num espaço virtual, informações referentes à formação e execução dos contratos públicos.

Palavras-chave: Portal Base; princípios; contratação pública; procedimento; contratos públicos.

\section{INTRODUÇÃO}

\subsection{Considerações gerais; conceito de contrato público}

O contrato público é um contrato, isto é, um acordo formado por duas (ou mais) declarações de vontade, que se ajustam para a produção de certos efeitos jurídicos. O contrato público deverá corresponder a um acordo dirigido à produção de efeitos jurídicos obrigatórios para uma ou para todas as partes que o subscrevem ${ }^{1}$ - cfr. Parte III do Código dos

\footnotetext{
${ }^{1}$ Para maiores desenvolvimentos sobre o conceito de contrato público, cfr. GONÇALVES, P. C., Direito dos Contratos Públicos, 3. a Ed., Vol. I, Almedina, Coimbra, 2018, pp. 20 e ss.
} 
Contratos Públicos português (doravante designado por CCP português), a respeito da noção de contrato administrativo.

Pode referir-se uma equivalência tendencial entre contrato público e contrato da Administração Pública, mas teremos de fazer aqui alguns afinamentos.

Tendo presente a referência legal ao conceito de contrato público ( $\mathrm{n} .{ }^{\circ} 2$ do artigo $1 .{ }^{\circ}$ do CCP português) e a ligação intrínseca do mesmo à figura subjetiva de entidade adjudicante (artigos $20^{\circ}$ e $7.0^{\circ}$ do CCP português), podemos considerar contrato público como "qualquer contrato celebrado por uma entidade adjudicante".

Contudo, há entidades adjudicantes que não integram a Administração Pública, pelo menos na delimitação desta, segundo um critério jurídicoadministrativo: tal sucede, por exemplo, com uma associação de direito civil sem fins lucrativos e sem associados públicos, maioritariamente financiada por dinheiros municipais num certo ano económico; ou com uma instituição particular de solidariedade social financiada pelo Estado.

A situação aqui referida (entidades adjudicantes e submetidas ao CCP português que não pertencem à Administração Pública, doravante abreviadamente designada por AP) também conhece o seu reverso, uma vez que há sujeitos da AP (em sentido funcional) que não se encontram legalmente elencados como entidades adjudicantes. É o caso das empresas públicas ou das empresas concessionárias de obras públicas e de serviços públicos, que exercem funções materialmente administrativas e que, por isso, devem considerar-se sujeitos da AP num sentido funcional. Ora, e tendo em conta o conceito de contrato público que o CCP português pressupõe - associado à categoria subjetiva de "entidade adjudicante" -, os contratos que essas entidades da AP celebram no âmbito do exercício de funções materialmente administrativas (n. 02 do artigo $3 .^{\circ}$ ) não são contratos públicos.

O conceito de contrato público nas diretivas da contratação pública compreende elementos de identificação de caráter orgânico - que indicam, por um lado, as partes ou os sujeitos do contrato (entidades adjudicantes); e, por outro, operadores económicos - e elementos de caráter substancial, que referenciam o objeto do contrato - execução de obras, fornecimento de produtos ou prestação de serviços -, qualificandoo como "contrato de aquisição", que envolve uma seleção do contratante e que não se reconduz a uma concessão de obras públicas ou de serviços. Um dos principais objetivos do CCP português trata-se do estabelecimento de uma disciplina aplicável ao Direito da Contratação Pública em conformidade com o Direito Europeu², o que ocorre, designadamente, a propósito do conteúdo da respetiva Parte II.

\footnotetext{
2 Precisamente neste sentido, veja-se AMARAL, D. F., Curso de Direito Administrativo, Vol. II, 3. a Ed. (reimpressão), Almedina, Coimbra, 2017, p. 471.
} 


\section{PRINCÍPIOS FUNDAMENTAIS DA CONTRATAÇÃO PÚBLICA}

\subsection{Generalidades}

Conforme estabelece o n. ${ }^{\circ} 1$ do artigo $1 .^{\circ}-A$ do CCP português, na formação e na execução dos contratos públicos devem ser respeitados os princípios gerais decorrentes da Constituição, dos Tratados da União Europeia e do Código do Procedimento Administrativo (doravante designado por CPA português), em especial os princípios da legalidade, da prossecução do interesse público, da imparcialidade, da proporcionalidade, da boa-fé, da tutela da confiança, da sustentabilidade e da responsabilidade, bem como os princípios da concorrência, da publicidade e da transparência, da igualdade de tratamento e da não-discriminação ${ }^{3}{ }^{4}$. Além disso, e conforme prevê o n.0 2 do mesmo artigo 1.0-A do CCP português, as entidades adjudicantes devem assegurar, na formação e na execução dos contratos públicos, que os operadores económicos respeitam as normas aplicáveis em vigor em matéria social, laboral, ambiental e de igualdade de género, decorrentes do direito internacional, europeu, nacional ou regional.

Sem prejuízo da aplicação das garantias de imparcialidade previstas no CPA português, as entidades adjudicantes devem adotar as medidas adequadas para impedir, identificar e resolver eficazmente os conflitos de interesses que surjam na condução dos procedimentos de formação de contratos públicos, de modo a evitar qualquer distorção da concorrência e garantir a igualdade de tratamento dos operadores económicos ( $n .{ }^{\circ} 3$ do artigo 1.0-A do CCP português).

Neste contexto, observem-se ainda os artigos $315 .^{\circ}$ (princípio da transparência); $281 .^{\circ}$ (princípios da conexão material e da proporcionalidade); 286.0 (princípio da boa fé); e 289.0 (princípio da colaboração recíproca), todos do CCP português, entre outros.

\subsection{Princípio da concorrência}

A concorrência trata-se de um valor central e prioritário no âmbito do Direito da Contratação Pública 5 , com forte dotação doutrinal e jurisprudencial ${ }^{6}$ no Direito Europeu, e surgindo como expressão da primazia da igualdade exigida à Administração Pública no tratamento igualitário de todos os operadores económicos. Como decorrência deste princípio, a entidade adjudicante tem de usar procedimentos de adjudicação abertos a todos os operadores económicos interessados (nisto

\footnotetext{
3 Para maiores desenvolvimentos sobre os princípios aplicáveis à contratação pública, cfr. GONÇALVES, P. C., Direito dos Contratos Públicos, 3. a Ed., Vol. I, Almedina, Coimbra, 2018, pp. 353 e ss.

4 Sobre os princípios estruturantes do Direito da Contratação Pública, veja-se, ainda, SÁNCHEZ, P. F., Direito da Contratação Pública, Vol. I., AAFDL Editora, 2020, pp. 51 e SS.

5 Neste mesmo sentido, veja-se GONÇALVES, P. C., Direito dos Contratos Públicos, 3.a Ed., Vol. I, Almedina, Coimbra, 2018, p. 354.

${ }^{6}$ Por exemplo, no Acórdão do Tribunal de Justiça da União Europeia, de 3 de junho de 2010 (proc. C-203/08) - Sporting Exchange Ltd, que age sob a denominação de «Betfair», contra Minister van Justitie.
} 
consiste a igualdade de acesso), tendo ainda de tratar igualmente todos os participantes (o que se afigura uma exigência de igualdade de tratamento). Além disso, no plano procedimental, e como se encontra em causa o acesso ou a entrada no mercado, o objetivo igualitário do princípio da concorrência não se prende com igualizar os concorrentes ou os seus poderes de oferta, mas apenas em igualizar as respetivas condições de participação (igualdade concorrencial) ${ }^{7}$.

O princípio da abertura à concorrência implica uma preferência por procedimentos de adjudicação abertos sobre os procedimentos de acesso limitado ou fechados ${ }^{8}$. A concorrência pode ser também vista como instrumento de proteção do interesse público financeiro ${ }^{9}$, concretizando-se em vários subprincípios no âmbito dos procedimentos concursais, como sejam os princípios da estabilidade das regras, das propostas e dos concorrentes; e o princípio da comparabilidade das propostas, por exemplo.

O CCP português consagra a ideia de concorrência ou de infração à concorrência como critério de decisão da entidade adjudicante, ao estabelecer, por exemplo, a possibilidade de decisão de recusar o acesso a informações que possam colocar em causa os valores da concorrência e da igualdade no âmbito de um procedimento de adjudicação; ou a decisão de excluir um agrupamento que integre todas as empresas que atuam num determinado setor da economia, como forma de abolir a concorrência ${ }^{10}$.

É precisamente em virtude do princípio da concorrência que são de rejeitar presunções iuris et de iure no tocante às causas de exclusão dos concorrentes, permitindo-se que a entidade adjudicante verifique, em concreto, a ocorrência de situações ou práticas suscetíveis de falsear a concorrência ${ }^{11}$.

Acresce que, muitas vezes, a concorrência é mesmo um critério de apreciação da legalidade de decisões e procedimentos das entidades adjudicantes ${ }^{12}$, por parte dos tribunais ${ }^{13}$.

\footnotetext{
7 Neste sentido, e para maiores desenvolvimentos, veja-se GONÇALVES, P. C., Direito dos Contratos Públicos, 3. ${ }^{a}$ Ed., Vol. I, Almedina, Coimbra, 2018, p. 355.

8 Para maiores desenvolvimentos, veja-se GONÇALVES, P. C., Direito dos Contratos Públicos, 3. a Ed., Vol. I, Almedina, Coimbra, 2018, pp. 355-356.

9 Cfr. GONÇALVES, P. C., Direito dos Contratos Públicos, 3. a Ed., Vol. I, Almedina, Coimbra, 2018, 2018, p. 356.

10 Cfr. GonÇALVES, P. C., Direito dos Contratos Públicos, 3.a Ed., Vol. I, Almedina, Coimbra, 2018, pp. 356-357.

${ }^{11}$ Cfr. GONÇALVES, P. C., Direito dos Contratos Públicos, 3.a Ed., Vol. I, Almedina, Coimbra, 2018, p. 358.

12 Cfr. GONÇALVES, P. C., Direito dos Contratos Públicos, 3. a Ed., Vol. I, Almedina, Coimbra, 2018, p. 358.

${ }^{13}$ A este propósito, veja-se, por exemplo, o Acórdão n. ${ }^{16 / 2011}$, do Tribunal de Contas português, referente ao Recurso ordinário n. ${ }^{\circ}$ 21/2011 - Processo n. ${ }^{\circ}$ 387/201 - Centro Hospitalar de S. João, E. P. E.; bem como o Acórdão do Tribunal de Justiça da União Europeia, de 15 de maio de 2008 (Processo C-147/06), SECAP SpA contra Comune di Torino,
} 


\subsection{Princípio da prossecução do interesse público}

A prossecução do interesse público ${ }^{14}$ trata-se da razão de ser da atividade da Administração Pública. O Direito Administrativo existe, entre outras coisas, para legitimar e regular a prossecução do interesse público por parte da Administração Pública.

Ora, o Direito da Contratação Pública surgiu também por exigências de interesse público, mais concretamente, no objetivo de zelar por uma boa utilização dos dinheiros públicos, isto é, pelo interesse público financeiro, através do best value for public money ${ }^{15}$.

Contudo, a este recorte financeiro acrescem outras dimensões do interesse público, como é o caso da utilização estratégica da contratação pública, com finalidades que passam pelo incentivo à inovação tecnológica, pela promoção da sustentabilidade, pelas políticas sociais e ambientais, etc. ${ }^{16}$

\subsection{Princípio da igualdade}

O princípio da igualdade encontra-se relacionado com a nãodiscriminação. A não-discriminação não se encontra referenciada no CCP português, tratando-se de um dos corolários do princípio da igualdade (este último, previsto nos art. ${ }^{\circ} \mathrm{s} 13 .{ }^{\circ}$ da Constituição da República Portuguesa e 6.0 do CPA português), e pretendendo aludir à nãodiscriminação em razão da nacionalidade ${ }^{17}$.

O princípio da igualdade, no âmbito do Direito da Contratação Pública, coloca-se no acesso aos procedimentos de adjudicação e, ainda, no que toca ao tratamento dos participantes nesses procedimentos ${ }^{18}$.

Assim, devem as entidades adjudicantes assegurar esta igualdade, quer na apresentação, quer na comparação, quer na avaliação das propostas. Quer isto dizer que todos os concorrentes deverão dispor das mesmas oportunidades na fase pré-contratual, encontrando-se submetidos às mesmas regras e condições ${ }^{19}$.

Acresce que a Diretiva 2014/24/UE vem estabelecer que os concursos não podem ser trabalhados de forma a reduzir artificialmente a concorrência, favorecendo ou desfavorecendo indevidamente determinados operadores económicos (cfr. segunda parte do n. ${ }^{\circ} 1$ do art. ${ }^{0} 18 .^{\circ}$ ). Proíbe-se, aqui, o favorecimento ou desfavorecimento indevidos. Não se excluem, por

\footnotetext{
14 Para maiores desenvolvimentos sobre o interesse público em Direito Administrativo, bem como sobre a respetiva evolução, veja-se, por exemplo: ALMEIDA, F. A. M. L. F., Direito Administrativo, Almedina, 2018, pp. 103-105; e CALVÃO, F. U., CAMPOS, M. F., BOTELHO, C. S., Introdução ao Direito Público, 4. a Ed., Almedina, 2019, p. 15.

15 Cfr. GONÇALVES, P. C., Direito dos Contratos Públicos, 3.a Ed., Vol. I, Almedina, Coimbra, 2018, p. 358.

${ }_{16}$ Cfr. GONÇALVES, P. C., Direito dos Contratos Públicos, 3.a Ed., Vol. I, Almedina, Coimbra, 2018, p. 358.

17 Cfr. GONÇALVES, P. C., Direito dos Contratos Públicos, 3.a Ed., Vol. I, Almedina, Coimbra, 2018, p. 359.

18 Cfr. GONÇALVES, P. C., Direito dos Contratos Públicos, 3.a Ed., Vol. I, Almedina, Coimbra, 2018, p. 359.

19 Para maiores desenvolvimentos, cfr. GONÇALVES, P. C., Direito dos Contratos Públicos, 3. ${ }^{a}$ Ed., Vol. I, Almedina, Coimbra, 2018, p. 360.
} 
exemplo, os contratos reservados, previstos nos art. ${ }^{\circ} \mathrm{s} 20.0^{\circ}$ e $77.0^{\circ}$ do CCP português ${ }^{20}$.

\subsection{Princípios da transparência e da publicidade}

O princípio da transparência tem como finalidade pugnar pela ausência do risco de favoritismos ou de qualquer outro tipo de arbítrio por parte da entidade adjudicante ${ }^{21}$. Este princípio implica que todas as condições e modalidades do procedimento de adjudicação se encontrem formuladas de forma clara, precisa e unívoca no anúncio ou nas peças do procedimento 22 23.

Ademais, todas as especificações técnicas tendentes à boa compreensão do anúncio e das peças do procedimento devem ser disponibilizadas aos operadores económicos que participam no procedimento, permitindo não apenas a compreensão, mas também colocar a entidade adjudicante em condições de verificar se, efetivamente, as propostas correspondem aos critérios estabelecidos no procedimento ${ }^{24}$.

O princípio da transparência previne eventuais conflitos de interesses e violações do princípio da imparcialidade (cfr. n. ${ }^{\circ} 3$ do art. ${ }^{0} 1.0-A$ do CCP português).

De notar que um dos corolários mais importantes do princípio da transparência prende-se com o dever de fundamentação das decisões tomadas no decurso dos procedimentos de formação dos contratos.

A transparência encontra-se ainda relacionada com a publicidade, o que se materializa no acesso, quer dos participantes no procedimento, quer do público, em geral, às decisões adotadas desde a adjudicação até aos ajustamentos ao contrato ${ }^{25}$.

20 Para maiores desenvolvimentos, cfr. GONÇALVES, P. C., Direito dos Contratos Públicos, 3. a Ed., Vol. I, Almedina, Coimbra, 2018, p. 362.

${ }^{21}$ Cfr. Acórdão do TJUE, de 16 de abril de 2015, SC Enterprise Focused Solutions SRL, Processo C-278/14.

${ }^{22}$ Cfr. Acórdão do TJUE, de 29 de abril de 2004, Comissão/CAS Succhi di Frutta, Processo C-496/99.

23 Segundo Pedro Costa Gonçalves, "(...) a obrigação de transparência impõe que a entidade adjudicante assegure um grau de publicidade adequado que permita não só promover a abertura à concorrência, como também controlar a prossecução do princípio da imparcialidade no procedimento pré-contratual. O princípio da transparência cumpre uma função importante na prevenção de conflitos de interesses e de eventuais violações do princípio da imparcialidade." - Cfr. GONÇALVES, P. C., Direito dos Contratos Públicos, 3. a Ed., Vol. I, Almedina, Coimbra, 2018, p. 363.

24 Para maiores desenvolvimentos, cfr. GONÇALVES, P. C., Direito dos Contratos Públicos, 3. a Ed., Vol. I, Almedina, Coimbra, 2018, pp. 362-363.

25 Para maiores desenvolvimentos, cfr. GONÇALVES, P. C., Direito dos Contratos Públicos, 3. a Ed., Vol. I, Almedina, Coimbra, 2018, pp. 362-365. 


\section{O PROCEDIMENTO DE FORMAÇÃO DOS CONTRATOS PÚBLICOS}

\subsection{Generalidades}

O procedimento de formação de contratos constitui a série ou a sucessão ordenada de atos que concorrem para a formação, a conclusão e a produção de uma plena eficácia jurídica de um contrato público ${ }^{26}$.

Segundo Francisco António de M. L. Ferreira de Almeida27, "[a]s exigências de procedimentalização da actividade administrativa fazem-se, efectivamente, sentir também no âmbito da celebração de contratos públicos. Daí que a escolha do co-contratante haja de ser precedida de um procedimento público, organizado de molde a que seja cumprido o princípio da transparência."

De acordo com o mesmo autor referenciado acima28, "[t]al procedimento não é, todavia, único e uniforme, pelo que, mais rigorosamente, dever-seia falar em procedimentos de formação dos contratos. Deparamo-nos, na verdade, com distintas tramitações legais em função dos vários tipos de contratos públicos. Ainda assim, é possível identificar elementos comuns à generalidade dos procedimentos, os quais nos permitem identificar as respetivas fases principais."

Em regra, o procedimento de formação dos contratos públicos apresentase como um procedimento legalmente regulado (princípio da legalidade procedimental) ${ }^{29}$.

Este princípio incide de forma particularmente intensa na disciplina dos procedimentos de seleção concorrencial, já que na fase de adjudicação participam vários interessados, em competição pelo acesso ao contrato e pelo benefício económico inerente ao mesmo.

O legislador define, com detalhe, os momentos que constituem a tramitação do procedimento, garantindo assim a imparcialidade e a igualdade de tratamento e de acesso ao procedimento (limitando o informalismo) e a latitude do princípio da adequação procedimental (art.o $56 .^{\circ}$ do CPA português).

Aliás, o próprio n. ${ }^{\circ} 1$ do artigo $201 .{ }^{\circ}$ do CPA português vem prever que a formação dos contratos cujo objeto abranja prestações que se estejam (ou sejam suscetíveis de estar) submetidas à concorrência, encontra-se sujeita ao regime estabelecido no CCP português ou em lei especial, sendo de destacar que se aplicam à formação dos contratos os princípios da transparência, da igualdade e da concorrência (n. ${ }^{\circ} 2$ do art. ${ }^{\circ} 201 .{ }^{\circ}$ do CPA português) ${ }^{30}$.

${ }^{26}$ Cfr. GonÇALVES, P. C., Direito dos Contratos Públicos, 3.a Ed., Vol. I, Almedina, Coimbra, 2018, pp. 109 e ss.

27 Cfr. ALMEIDA, F. A. M. L. F., Direito Administrativo, Almedina, Coimbra, 2018, p. 256.

28 Cfr. ALMEIDA, F. A. M. L. F., Direito Administrativo, Almedina, Coimbra, 2018, p. 256.

29 Para maiores desenvolvimentos, veja-se GONÇALVES, P. C., Direito dos Contratos Públicos, 3. a Ed., Vol. I, Almedina, Coimbra, 2018, pp. 110-112.

${ }^{30}$ Conforme referem OLIVEIRA, F. P. e DIAS, J. E. F., in Noções Fundamentais de Direito Administrativo, 5. a Ed. (reimpressão), Almedina, Coimbra, 2019, pp. 306-307, nota de rodapé n. ${ }^{\circ}$ 291, a transparência dos contratos públicos, concretamente dos respetivos procedimentos pré-contratuais, foi reforçada designadamente pelo Decreto-Lei $n .{ }^{\circ}$ $131 / 2010$, de 14 de dezembro. A novidade mais significativa prende-se com a introdução 
Existe ainda, no CCP português, um princípio de tipificação taxativa dos procedimentos de adjudicação, uma vez que as entidades adjudicantes têm de adotar na formação de contratos um dos tipos de procedimentos que a lei prevê (art. ${ }^{\circ} 16 .{ }^{\circ}, n^{\circ} 1$ ), encontrando-se vedada a possibilidade de criar espécies procedimentais novas ou regimes mistos ${ }^{31}$.

Destarte podemos identificar uma fase preparatória ou pré-contratual (que inclui a fase de iniciativa e a fase da instrução) e uma fase decisória32.

Outros autores ${ }^{33}$ referem, alternativamente: (i) a fase preparatória, que integra todos os atos jurídicos prévios dirigidos à conclusão do contrato público, subdividindo-se na fase de iniciativa e na fase de instrução; (ii) a fase principal ou conclusiva, que consiste na celebração e outorga do contrato; e (iii) a fase integrativa da eficácia (ou complementar), aplicável quando a lei faça depender a eficácia do contrato de atos integrativos da eficácia.

\subsection{Fase preparatória ou pré-contratual}

A fase preparatória antecede a celebração ou outorga do contrato público, nela se incluindo todos os atos jurídicos que devem ser praticados, com vista a alcançar o resultado final almejado, isto é, a conclusão do contrato. Da fase preparatória (ou pré-contratual) fazem parte a fase da iniciativa e a fase da instrução.

A fase da iniciativa engloba a decisão de contratar (e a autorização de despesa), a decisão de escolha do procedimento a adotar ${ }^{34}$, o aviso de abertura e a elaboração das peças do procedimento. Quer a decisão de contratar, quer a decisão de escolha do procedimento a adotar constituem atos internosmas que adquirem eficácia externa com a publicitação do aviso de abertura do concurso, sendo que a partir desse momento surge na ordem jurídica um ato administrativo impugnável.

do mecanismo do anúncio voluntário de transparência, previsto no artigo $78 .^{\circ}-\mathrm{A}$ do CCP português.

${ }^{31}$ Neste sentido, cfr. GONÇALVES, P. C., Direito dos Contratos Públicos, 3. a Ed., Vol. I, Almedina, Coimbra, 2018, pp. 110-111.

32 Neste mesmo sentido, cfr. ALMEIDA, F. A. M. L. F., Direito Administrativo, Almedina, Coimbra, 2018, pp. 256-263.

${ }^{33}$ Como é o caso de OLIVEIRA, F. P. e DIAS, J. E. F., in Noções Fundamentais de Direito Administrativo, 5. a Ed. (reimpressão), Almedina, Coimbra, 2019, pp. 306-318. É também o caso de GONÇALVES, P. C., Direito dos Contratos Públicos, 3. a Ed., Vol. I, Almedina, Coimbra, 2018, p. 112.

${ }^{34}$ Conforme prevê o artigo $38 .^{\circ}$ do CCP português, esta decisão deve ser devidamente fundamentada e tomada pelo órgão competente para a decisão de contratar. Os critérios que devem ser adotados na escolha do procedimento pré-contratual podem ser quantitativos (isto é, em função do valor do contrato) ou materiais, que são aqueles quer permitem a celebração de contratos através de determinados procedimentos, independentemente do valor do contrato, por se encontrarem em causa interesses que devem prevalecer à estrita liberdade concorrencial. Para maiores desenvolvimentos, cfr. OLIVEIRA, F. P. e DIAS, J. E. F., Noções Fundamentais de Direito Administrativo, 5. a Ed. (reimpressão), Almedina, Coimbra, 2019, pp. 309-310. 
É também nesta fase que são elaboradas as peças do procedimento ${ }^{35}$ (artigo $40.0^{\circ}$ do CCP português), que são o convite à apresentação de propostas (no ajuste direto, no concurso limitado por prévia qualificação e no procedimento de negociação) ou à apresentação de soluções (no diálogo concorrencial), o programa do procedimento (em todos os procedimentos, à exceção do ajuste direto) e o caderno de encargos (em todos os procedimentos, à exceção do ajuste direto simplificado - artigo $128 .^{\circ}$ do CCP português).

Por seu turno, a fase da instrução (que integra, ainda, a fase preparatória ou pré-contratual) inclui a apresentação das candidaturas e a qualificação dos interessados (quando o procedimento em causa assim o contemple), a apresentação e avaliação das propostas e a preparação da adjudicação.

A apresentação de candidaturas e a qualificação dos interessados ocorrem no âmbito do concurso limitado por prévia qualificação, para o qual remetem os procedimentos de negociação e o diálogo concorrencial.

Analisadas as candidaturas apresentadas, o júri do procedimento procede à respetiva apreciação, baseando-se na avaliação da capacidade técnica e financeira dos interessados. Seguidamente, é elaborado um relatório preliminar, no qual o júri propõe a qualificação dos candidatos e, quando aplicável, a exclusão das candidaturas (n.0 2 do artigo $184.0^{\circ}$ do CCP português). Perante o relatório preliminar, os interessados podem formular as observações que entendam, em sede de audiência prévia, ao que se segue a elaboração do relatório final.

O relatório final e os demais documentos que fazem parte do procedimento pré-contratual são remetidos ao órgão competente para a decisão de contratar, que fica habilitado a tomar a decisão de qualificação, propriamente dita. Esta decisão de qualificação constitui pressuposto de convite à apresentação de proposta aos candidatos que tenham sido qualificados (artigo $186 .^{\circ}$ do CCP português).

Já no que concerne à apresentação e avaliação das propostas ${ }^{36}$, refira-se que, conforme o artigo $56 .{ }^{\circ}$ do CCP português, proposta consiste numa declaração mediante a qual o concorrente manifesta à entidade pública a sua intenção de contratar, dando-Ihe conta do modo como se dispõe a fazê-lo, com base nas peças do procedimento, designadamente caderno de encargos e programa do procedimento. Note-se que, dentro dos limites previstos no CCP português para cada procedimento, o prazo para apresentação das propostas fixado pela entidade adjudicante deverá ajustar-se à natureza e complexidade das prestações contratuais.

35 Cfr. AMARAL, D. F., Curso de Direito Administrativo, Vol. II, 3.a Ed. (reimpressão), Almedina, Coimbra, 2017, p. 484.

${ }^{36} \mathrm{O}$ momento em que a apresentação de propostas tem lugar varia em função do tipo de procedimento. Deste modo, a apresentação de propostas inicia-se após o convite às entidades escolhidas, no caso do ajuste direto (artigo $115 .{ }^{\circ}$ do CCP português); na sequência da publicação do anúncio, no caso do concurso público (artigo $135 .{ }^{\circ}$ do CCP português); após o convite aos candidatos qualificados, nas hipóteses de concurso limitado por prévia qualificação e de procedimento de negociação (artigo 199. do CCP português); e após o convite aos candidatos qualificados, cujas soluções tenham sido admitidas, no caso do diálogo concorrencial (artigo $217 .{ }^{\circ}$ do CCP português). 
Até ao termo do prazo fixado para a apresentação das propostas, os interessados que já as tenham apresentado podem retirá-las, bastando comunicar tal facto à entidade adjudicante (artigo $137 .{ }^{\circ}$ do CCP português). Contudo, terminado esse prazo, os concorrentes são obrigados a manter as respetivas propostas nos 66 dias contados da data do termo do prazo fixado (artigo $65 .^{\circ}$ do CCP português).

Findo o prazo para apresentação das propostas, o júri procede à publicação da lista dos concorrentes e das respetivas propostas. Analisadas as propostas (artigo $700^{\circ}$ do CCP português), segue-se a avaliação das que não devam ser excluídas (n. ${ }^{\circ} \mathrm{s} 2$ e ss do artigo $70.0^{\circ} \mathrm{e}$ n. 02 do artigo $146 .^{\circ}$, ambos do CCP português).

Por seu turno, e nos termos do n. ${ }^{\circ} 1$ do artigo $74 .^{\circ}$ do CCP português, a adjudicação é feita de acordo com o critério da proposta economicamente mais vantajosa para a entidade adjudicante, determinada por uma das seguintes modalidades:

(i) melhor relação qualidade-preço, na qual o critério de adjudicação é composto por um conjunto de fatores, e eventuais subfatores, relacionados com diversos aspetos da execução do contrato a celebrar;

(ii) avaliação do preço ou custo enquanto único aspeto da execução do contrato a celebrar, modalidade que só pode ser adotada quando as peças do procedimento definam todos os restantes aspetos da execução do contrato a celebrar ${ }^{37}$.

Os fatores e os eventuais subfatores que densificam o critério de adjudicação da proposta economicamente mais vantajosa devem estar ligados ao objeto do contrato a celebrar, abrangendo todos, e apenas, os aspetos da execução do contrato a celebrar submetidos à concorrência pelo caderno de encargos (artigo 75.0, n.o 1 do CCP português).

Finda a instrução (com o momento da preparação da adjudicação), o júri elabora um relatório preliminar, ao qual se segue a fase da audição prévia, e um relatório final, o qual deve ser fundamentando e pode (ou não) manter o teor das conclusões constantes no relatório preliminar. Neste momento, o júri pode também propor a exclusão de qualquer proposta (n.0 2 do artigo $146 .{ }^{\circ}$ do CCP português).

Por último, temos o envio do relatório final e demais documentos do concurso ao órgão adjudicante (n.o 3 do artigo $148 .{ }^{\circ}$ do CCP português) $)^{38}$.

\subsection{Fase decisória}

A fase decisória trata-se daquela em que o contrato é celebrado. De acordo com o previsto no n.o 4 do artigo 148.0 do CCP português, compete ao órgão adjudicante decidir sobre a aprovação de todas as propostas contidas no relatório final. Assim, o órgão adjudicante decidirá

37 Para maiores desenvolvimentos, cfr. OLIVEIRA, F. P. e DIAS, J. E. F., Noções Fundamentais de Direito Administrativo, 5. ${ }^{a}$ Ed. (reimpressão), Almedina, Coimbra, 2019 , p. 315.

38 Para maiores desenvolvimentos sobre a fase preparatória, que acabamos de expor, cfr. ALMEIDA, F. A. M. L. F., Direito Administrativo, Almedina, Coimbra, 2018, pp. 257-261 que, aliás, serviu de base principal a esta parte da nossa exposição. 
sobre a hipotética exclusão de propostas e, ainda, sobre a ordenação das propostas não excluídas.

A adjudicação finaliza o procedimento pré-contratual, sendo da competência do órgão a quem incumbe tomar a decisão de contratar e deve ser notificada aos concorrentes até ao termo do prazo da obrigação de manutenção das propostas. Na hipótese de ser excedido este prazo, a entidade adjudicante deve fundamentar o seu atraso, verificando-se o direito de recusa da adjudicação pelo concorrente cuja proposta for escolhida, bem como o dever de indemnização pelos encargos em que comprovadamente o concorrente tenha incorrido com a elaboração da respetiva proposta (artigo $76 .^{\circ}$ do CCP português) ${ }^{39}$.

Nas palavras de Marcello Caetano40, "[a] adjudicação é o acto administrativo pelo qual a autoridade competente escolhe, de entre as várias propostas admitidas ao concurso, aquela que é preferida para a elaboração do contrato (...). O concorrente preferido torna-se então o adjudicatário, isto é, o proponente escolhido para celebrar o contrato com a pessoa colectiva de direito público".

A adjudicação deve ser publicada através de anúncio no Jornal Oficial da União Europeia (JOUE), no prazo de 30 dias após a adjudicação.

Neste contexto, note-se que o artigo 79.0 do CCP português vem prever causas de não adjudicação, que determinam a revogação da decisão de contratar (artigo 80.0 do CCP português).

Ressalve-se também que, antes da celebração do contrato, existem ainda alguns procedimentos a cumprir, como é o caso da apresentação dos documentos de habilitação ${ }^{41}$. Neste contexto, o adjudicatário tem o dever de entregar os documentos comprovativos da sua habilitação para a execução do contrato, que se prendem, designadamente, com a inexistência de dívidas à Autoridade Tributária e Aduaneira ou à Segurança Social e a não condenação por crime que atente contra a honorabilidade profissional.

Nesta fase, temos ainda a prestação de caução ${ }^{42}$ pelo adjudicatário, no caso de contratos que exijam o pagamento de um preço pela entidade adjudicante, como forma de garantir a celebração do contrato e o cumprimento das obrigações dele emergentes.

Acresce que se se encontrarem envolvidas terceiras entidades, temos ainda a confirmação dos compromissos assumidos por tais entidades, relativos a atributos ou a termos e condições da proposta adjudicada. Conforme prevê o artigo $93 .^{\circ}$ do CCP português, a não apresentação da confirmação dos compromissos é causa de caducidade da adjudicação.

\footnotetext{
${ }^{39}$ Neste mesmo sentido, veja-se OLIVEIRA, F. P. e DIAS, J. E. F., Noções Fundamentais de Direito Administrativo, 5. a Ed. (reimpressão), Almedina, Coimbra, 2019, p. 316.

40 Cfr. CAETANO, M., Manual de Direito Administrativo, Tomo I, 10.a Ed., 10.a reimpressão, Almedina, Coimbra, 2020, p. 603.

${ }^{41}$ Alínea a) do n. ${ }^{\circ} 2$ do artigo $77.0^{\circ}$ e artigo $81 .^{\circ}$, ambos do CCP português.

${ }^{42}$ Alínea b) do n. ${ }^{\circ} 2$ do artigo $77.0^{\circ}$ e artigos $88 .{ }^{\circ}$ e ss, todos do CCP português.
} 
Termina esta fase com a celebração do contrato e a outorga do mesmo ${ }^{43}$. A celebração do contrato, regulada nos artigos $94 .{ }^{\circ}$ e seguintes do CCP português, culmina com a outorga do contrato, que se traduz na assinatura do mesmo, quer pela entidade adjudicante (representada pelo órgão competente para a decisão de contratar), quer pelo adjudicatário ou seu representante ${ }^{44}$.

Nos casos em que a celebração do contrato implique a sua redução a escrito, a respetiva minuta é aprovada pelo órgão competente para a decisão de contratar em simultâneo com a decisão de adjudicação (artigo $98 .{ }^{\circ}$, n. ${ }^{\circ} 1$ do CCP português).

Via de regra, a outorga do contrato deve ter lugar no prazo de 30 dias contados da data da aceitação da minuta ou da decisão sobre a reclamação (cfr. proémio do $\mathrm{n} .^{\circ} 1$ do artigo $104 .{ }^{\circ}$ do CCP português), mas nunca antes de decorridos 10 dias (isto é, o período de stand still, exigido pelas diretivas da União Europeia) contados da notificação da decisão ao adjudicatário, de apresentados todos os documentos de habilitação e de comprovada a prestação de caução, quando esta seja exigível ${ }^{45}$.

\section{A IMPORTÂNCIA DO PORTAL BASE E AS FERRAMENTAS QUE OFERECE}

O objetivo principal do portal Base é o de divulgar informação sobre os contratos públicos celebrados em Portugal sujeitos ao regime do CCP português. Para dar cumprimento a este objetivo, o portal constitui-se como uma ferramenta tecnológica que centraliza, num espaço virtual, informações referentes à formação e execução dos contratos públicos. Este repositório de informação é de acesso público, podendo ser consultado por qualquer indivíduo.

\subsection{A interação do utilizador com o Portal Base}

A informação no portal está organizada por contrato, e divide-se em duas secções principais: informação sobre a formação do contrato e informação sobre a sua execução. A informação sobre a formação do contrato inclui elementos como o tipo de contrato, a sua descrição, o tipo de procedimento, uma fundamentação, nome e número de identificação fiscal (NIF) das entidades adjudicatária e adjudicante, o objeto do contrato, a sua data de celebração, o preço estipulado ou o prazo e local de execução. A informação relativa à execução do contrato consiste na data de fecho, o preço total efetivo bem como descrições de eventuais causas para alterações ao prazo ou preço de execução.

${ }^{43}$ Para maiores desenvolvimentos sobre a fase decisória, que acabamos de expor, cfr. ALMEIDA, F. A. M. L. F., Direito Administrativo, Almedina, Coimbra, 2018, pp. 261-263 que, aliás, serviu de base principal a esta parte da nossa exposição.

44 Para maiores desenvolvimentos, cfr. AMARAL, D. F. Curso de Direito Administrativo, Vol. II, 3. a Ed. (reimpressão), Almedina, Coimbra, 2017, pp. 488-489.

${ }_{45}$ Neste sentido, veja-se OLIVEIRA, F. P. e DIAS, J. E. F., Noções Fundamentais de Direito Administrativo, 5. a Ed. (reimpressão), Almedina, Coimbra, 2019, p. 317-318. 
O acesso a esta informação é feito através da funcionalidade de pesquisa, que tem duas modalidades principais: pesquisa simples e pesquisa avançada.

$\mathrm{Na}$ pesquisa simples, o utilizador introduz na caixa de pesquisa um ou mais termos, que são utilizados como uma conjunção lógia. Ou seja, apenas os contratos que incluam simultaneamente todos os termos, em um ou mais campos, são retornados. Por exemplo, a pesquisa pelo termo "chaves" pode retornar contratos:

- Cujo local de execução seja a cidade de Chaves, no distrito de Vila Real;

- Cujo objeto seja a aquisição de chaves ou sistemas/centrais de segurança com guarda de chaves;

- Cujo nome das entidades adjudicantes ou adjudicatárias inclua o termo chaves;

$\mathrm{Na}$ pesquisa avançada, o utilizador tem a possibilidade de ser mais específico e mais eficientemente dirigir a pesquisa e os resultados para a necessidade de informação que pretende satisfazer. Entre outros, o utilizador pode pesquisar por tipo de procedimento ou de contrato, por preço contratual ou efetivo, datas e prazo de execução ou local de execução em termos de país, distrito ou concelho. Também aqui os termos da pesquisa são tratados como uma conjunção lógica.

Os resultados da pesquisa são apresentados ao utilizador em formato tabular. Cada linha apresenta um contrato, e para cada contrato são apresentados o seu objeto, o preço contratual, a data de publicação no portal Base, bem como os nomes das entidades adjudicante e adjudicatária. Esta tabela de resultados pretende ser apenas um resumo da informação mais importante, estando um maior nível de detalhe para cada contrato disponível através de uma hiperligação. Os resultados estão, por defeito, ordenados decrescentemente por data de publicação no portal. No entanto, esta ordenação pode ser mudada pelo utilizador clicando no nome de cada uma das cinco colunas apresentadas.

$\mathrm{Na}$ apresentação dos resultados de qualquer modalidade de pesquisa existe ainda um mecanismo de paginação que apresenta 25 contratos por página de forma a não sobrecarregar o meio de comunicação digital utilizado entre o servidor e o dispositivo do cliente, e a não assoberbar o utilizador com excesso de informação.

Por último, é ainda possível ao utilizador exportar os resultados da pesquisa e descarregá-los para o seu dispositivo sob a forma de uma folha de cálculo Excel. Isto permite ao utilizador uma posterior análise e transformação dos dados resultantes da sua pesquisa.

\subsection{A importância dos modelos de dados}

O portal Base, através da indexação e disponibilização de informação acerca dos contratos públicos em Portugal, contribui efetivamente para uma maior transparência e igualdade na Contratação Pública, bem como para uma concorrência mais justa e saudável entre as organizações adjudicatárias, favorecendo assim a prossecução do interesse público. 
Este contributo é, no entanto, limitado no seu alcance. Isto acontece especialmente pelo formato tabular escolhido para a representação e apresentação da informação. Este formato tabular está intimamente ligado às chamadas Bases de Dados Relacionais. Estas Bases de Dados assentam no modelo relacional de dados, em que todos os dados são guardados sob a forma de tabelas (relações), e em que existem relacionamentos entre tabelas que definem como os dados se relacionam entre si. Assim, tomando como exemplo o domínio da contratação pública, podem existir os conceitos "Organização", representando entidades públicas ou empresas, e "Contrato", representando a realização de um contrato público entre duas ou mais organizações.

Cada um destes conceitos é representado na forma de uma tabela. Assim, cada linha representa uma instância diferente desse conceito, e cada coluna representa uma propriedade ou característica do respetivo conceito. Relacionamentos entre conceitos são modelados utilizando colunas especialmente criadas para o efeito numa das tabelas. Assim, para modelar o relacionamento entre as entidades "Organização" e "Contrato", poderia ser criada uma ou mais novas colunas na tabela "Contrato" que passariam a conter os identificadores das organizações que participam no contrato, permitindo assim ligar os dados.

Este modelo de dados, criado na década de 70, continua a ser a base da grande maioria dos Sistemas de Informação existente. Independentemente das suas reconhecidas potencialidades, há domínios em que apresenta também limitações. Isto acontece, especialmente, em domínios em que o foco está tanto ou mais no relacionamento do que na entidade. O exemplo maior deste domínio são as redes sociais digitais atuais, em que a maioria do valor reside não nas diferentes entidades (e.g. utilizadores, páginas) mas nos relacionamentos entre si.

Para dar resposta a esta nova realidade surgiram em anos recentes, fortemente impulsionadas por empresas como a Facebook e a Google, as denominadas Bases de Dados Orientadas a Grafos. Ao contrário das Bases de Dados relacionais, baseadas em Lógica e Teoria de Conjuntos, uma Base de Dados Orientada a Grafos é baseada na Teoria de Grafos. Assim, existem os conceitos de nó ou vértice, que representa uma instância de uma entidade, e o conceito de aresta, que representa um relacionamento entre dois nós. Seguindo o exemplo anterior, cada organização seria representada numa Base de Dados Orientada a Grafos como um nó ou um ponto, com as suas respetivas propriedades, e cada contrato como um relacionamento entre nós. Assim, cada dois nós têm entre si tantos relacionamentos ou arestas quantos os contratos em que tenham participado em conjunto. Para além disso, cada aresta tem um conjunto de propriedades que, neste exemplo, descrevem as propriedades de um contrato específico, tais como o seu preço ou a sua data. Por último, a aresta pode também ter uma direção o que, a acontecer, contém também informação. Neste exemplo, uma aresta entre dois nós $A$ e $B$, direcionada de $A$ para $B$, poderia modelar um contrato entre $A$ e $B$ em que $A$ é a entidade adjudicante e $B$ a entidade adjudicatária. A principal característica deste novo modelo de dados é precisamente a relevância 
que é dada ao relacionamento, que passa para primeiro plano, e a riqueza que isto comporta numa perspetiva de armazenamento e análise de dados.

\subsection{As potencialidades do Portal Base}

O domínio da Contratação Pública é, a par de outros como as redes sociais, um em que uma parte significativa da informação existe ao nível dos relacionamentos entre as entidades. De facto, quando se analisa o CCP português, verifica-se que muitas das situações contempladas incidem sobre os relacionamentos (isto é, contratos ou conjuntos deles), entre duas ou mais entidades, em determinadas janelas temporais, tendo em conta determinados limites, nesse Código prescritos (por exemplo, consoante o tipo de procedimento contratual em causa). Ora, este tipo de situação é difícil de verificar numa representação tabular dos dados.

Mais natural seria fazê-lo utilizando uma representação baseada em grafos, em que os dados são representados num plano bidimensional: as organizações enquanto pontos e os contratos entre si enquanto linhas ou setas que unem pares de pontos. De facto, em domínios como este, a visualização deste tipo de informação na forma de um grafo é mais intuitiva por várias razões:

- Organizações (nós) que se relacionam de forma mais intensa, por terem um maior número ou valor de contratos, são representados mais próximos no plano;

- $\quad$ Número de contratos entre entidades é facilmente visível pelo número de linhas que as ligam;

- Valor de cada contrato pode ser representado pela espessura da linha utilizada, permitindo facilmente perceber e comparar a magnitude de cada contrato;

- Relevância ou centralidade de cada organização pode ser representada pelo tamanho do seu nó;

- Clusters ou agrupamentos de organizações são evidentes pela sua representação próxima no mapa, permitindo perceber que conjuntos de organizações estão mais relacionadas entre si, bem como que organizações têm poucos relacionamentos ou relacionamentos muito específicos;

- $\quad$ Organizações podem também ser dispostas no plano de forma georreferenciada, de acordo com a sua localização, permitindo facilmente analisar a dinâmica da contratação pública dentro de e entre regiões. Esta representação pode, inclusivamente, usar como plano um mapa digital, permitindo assim observar cada organização na sua localização real.

As vantagens até agora mencionadas têm que ver, sobretudo, com a visualização da informação por um utilizador humano. De facto, os mesmos dados podem ser representados de uma forma diferente e, por esse meio apenas, transmitir ao utilizador uma maior quantidade de informação, facilitando assim a sua análise ou dando uma melhor resposta à sua necessidade de informação. 
Existem, no entanto, outras vantagens na utilização de um modelo de dados orientado a grafos. Nomeadamente, tem sido desenvolvida toda uma panóplia de algoritmos baseados na Teoria de Grafos que permitem enriquecer a camada de análise de dados numa plataforma deste tipo. Estes algoritmos incluem algoritmos de caminho mais curto (que calculam o menor conjunto de organizações que permitem estabelecer a ligação entre duas organizações específicas), algoritmos de centralidade (que permitem determinar que organizações desempenham um papel fundamental na contratação pública), algoritmos de similaridade (que comparam vértices em termos das arestas que partilham), entre outros. Especialmente interessantes são os algoritmos que assentam sobre a estrutura do grafo, tal como os de centralidade, por permitirem analisar de um nível muito alto a forma como as entidades se relacionam, algo que é impossível de fazer com uma representação tabular dos dados.

Esta mudança na forma de representar e apresentar os dados no portal Base poderia assim permitir-Ihe cumprir os seus objetivos de forma muito mais eficiente. De facto, estes dados, quando tratados como um grafo, têm o potencial de gerar uma maior quantidade de informação, o que facilitaria e melhoraria as análises que são levadas a cabo no portal Base. Isto teria um impacto positivo a diferentes níveis, e em especial no que diz respeito a atividades de deteção de irregularidades ou fraude, especialmente tipos mais complexos de fraude envolvendo relacionamentos entre várias entidades. Permitiria, ainda, utilizar métodos automáticos de deteção de padrões baseados em subcampos da Inteligência Artificial, melhorando significativamente a eficácia e abrangência deste tipo de análises.

\section{CONCLUSÕES}

Refere o CCP português que, na formação e na execução dos contratos públicos, devem ser respeitados os princípios gerais decorrentes da Constituição, dos Tratados da União Europeia e do CPA português, em especial os princípios da legalidade, da prossecução do interesse público, da imparcialidade, da proporcionalidade, da boa-fé, da tutela da confiança, da sustentabilidade e da responsabilidade, bem como os princípios da concorrência, da publicidade e da transparência, da igualdade de tratamento e da não-discriminação.

O procedimento de formação de contratos constitui a série ou a sucessão ordenada de atos que concorrem para a formação, a conclusão e a produção de uma plena eficácia jurídica de um contrato público.

O legislador define, com detalhe, no CCP português, os momentos que constituem a tramitação do procedimento de formação dos contratos públicos (com algumas especificidades mediante o tipo de procedimento, que terá de ser um dos que se encontram elencados no CCP português), numa lógica de transparência, garantindo a imparcialidade e a igualdade de tratamento e de acesso ao procedimento (limitando o informalismo) e a latitude do princípio da adequação procedimental.

Neste contexto, e sem prejuízo da aplicação das garantias de imparcialidade previstas no CPA português, as entidades adjudicantes 
devem adotar as medidas adequadas para impedir, identificar e resolver eficazmente os conflitos de interesses que surjam na condução dos procedimentos de formação de contratos públicos, de modo a evitar qualquer distorção da concorrência e garantir a igualdade de tratamento dos operadores económicos.

Aliás, o próprio CPA português vem prever que a formação dos contratos cujo objeto abranja prestações que se estejam (ou sejam suscetíveis de estar) submetidas à concorrência, encontra-se sujeita ao regime estabelecido no CCP português ou em lei especial, sendo de destacar que se aplicam à formação dos contratos os princípios da transparência, da igualdade e da concorrência.

O objetivo principal do portal Base é o de divulgar informação sobre os contratos públicos celebrados em Portugal sujeitos ao regime do CCP português. Para dar cumprimento a este objetivo, o portal constitui-se como uma ferramenta tecnológica que centraliza, num espaço virtual, informações referentes à formação e execução dos contratos públicos. Este repositório de informação é de acesso público, podendo ser consultado por qualquer indivíduo.

A forma "tradicional" de representar e apresentar informação, na forma de tabela, é limitada pois não permite visualizar facilmente a forma como as entidades se relacionam.

O domínio da Contratação Pública é, a par de outros como as redes sociais, um em que uma parte significativa da informação existe ao nível dos relacionamentos entre as entidades.

No entanto, o portal base, pelo seu foco no contrato individual, quer ao nível da visualização quer ao nível do acesso à informação, dificulta a prossecução de alguns dos princípios fundamentais do Direito da Contratação Pública, quer ao nível de Portugal, quer ao nível da União Europeia, nomeadamente no que diz respeito à legalidade, transparência e concorrência.

O melhor exemplo é talvez o do particionamento de despesas. Um potencial contrato de elevado valor, que é partido em vários de valor inferior, de forma a cada um, individualmente, não ultrapassar determinados limites, surge no portal base como diferentes entradas, sem qualquer relação entre si. Cabe ao utilizador obter a informação e tratá-la de forma a perceber quais desses contratos estão relacionados e podem eventualmente fazer parte de um esquema de particionamento de despesas. Já na abordagem proposta, estes contratos seriam imediatamente visíveis através de um número elevado ou anormal de ligações entre uma entidade pública e uma privada, permitindo mais facilmente a sua deteção e investigação.

Assim, a utilização de um modelo de dados orientado a grafos não só melhora significativamente a representação visual dos dados, facilitando a comunicação com o utilizador Humano, como permite a utilização de algoritmos de grafos que melhoram a quantidade e valor da informação gerada.

\section{BIBLIOGRAFIA}


ALMEIDA, F. A. M. L. F., Direito Administrativo, Almedina, Coimbra, 2018.

AMARAL, D. F., Curso de Direito Administrativo, Vol. II, 3.a Ed. (reimpressão), Almedina, Coimbra, 2017.

CAETANO, M., Manual de Direito Administrativo, Tomo I, 10.a Ed., 10.a reimpressão, Almedina, Coimbra, 2020.

CALVÃO, F. U., CAMPOS, M. F., BOTELHO, C. S., Introdução ao Direito Público, 4.a Ed., Almedina, 2019.

GONÇALVES, P. C., Direito dos Contratos Públicos, 3.a Ed., Vol. I, Almedina, Coimbra, 2018.

OLIVEIRA, F. P. e DIAS, J. E. F., in Noções Fundamentais de Direito Administrativo, 5. a Ed. (reimpressão), Almedina, Coimbra, 2019.

SÁNCHEZ, P. F., Direito da Contratação Pública, Vol. I., AAFDL Editora, 2020. 